\title{
Karakterisasi dispersi padat meloksikam dengan matriks campuran PEG 6000 dan poloxamer 188 yang dibuat menggunakan metode kombinasi
}

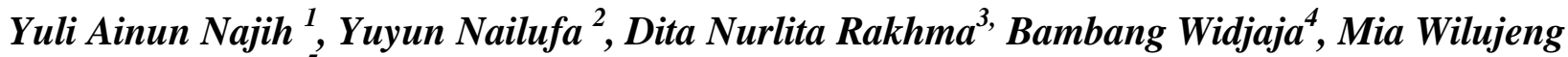 \\ Fatkhur Dzariasil ${ }^{5}$ \\ ${ }^{1,2,3,4}$ Program Studi Farmasi, Fakultas Kedokteran, Universitas Hang Tuah, Surabaya, Indonesia
}

\section{INFO ARTIKEL \\ Sejarah artikel: \\ Penerimaan \\ naskah: 1 \\ Desember 2020 \\ Penerimaan \\ naskah revisi: 26 \\ Desember 2021 \\ Disetujui untuk \\ dipublikasikan: 4 \\ Mei 2021}

Kata kunci :

Meloksikam, PEG

6000, Poloxamer

188, Dispersi

Padat, Metode

Kombinasi,

Karakterisasi

\section{A B S T R A K}

Meloksikam merupakan salah satu obat golongan NSAID yang diindikasikan untuk meringankan rasa sakit dan peradangan pada penyakit rematik. Klasifikasi obat meloksikam termasuk dalam Biopharmaceutics Classification System (BCS) kelas II, yang memiliki kelarutan rendah dan permeabilitas tinggi, hal tersebut dapat mengakibatkan pembatasan penyerapan obat dalam tubuh. Salah satu upaya yang dilakukan pada penelitian ini untuk meningkatkan kelarutan meloksikam yaitu dengan melakukan pembentukan sistem dispersi padat meloksikam dalam campuran PEG 6000 dan poloxamer 188 pada perbandingan 99:1 dan 98:2 dengan metode kombinasi yang kemudian dibandingkan dengan campuran fisiknya pada perbandingan yang sama dan senyawa murninya. Penelitian ini dilakukan bertujuan untuk mengetahui karakteristik dari masing-masing sediaan tersebut. Pada hasil difraktogram menggunakan XRPD, dispersi padat dengan perbandingan 99:1 dan 98:2 menunjukkan terbentuknya puncak dengan tingkat ketajaman atau instensitas yang lebih kecil pada sudut $13,5^{\circ} ; 15,0^{\circ}$; dan $18,5^{\circ}$. Data termogram menggunakan DSC menunjukkan adanya penurunan derajat kristanilitas pada sistem dispersi padat dengan perbandingan 99:1 dan 98:2 yaitu pada titik lebur $56,1^{\circ} \mathrm{C}$ dan $55,4^{\circ} \mathrm{C}$. Hasil karakterisasi dengan FT-IR menunjukkan bahwa spektra yang teridentifikasi berada pada kisaran spektra meloksikam, PEG 6000, dan poloxamer 188, Hal tersebut menunjukkan bahwa sistem dispersi padat tidak terjadi interaksi kimia antara meloksikam dengan PEG 6000 dan poloxamer 188.

\section{Karakterisasi dispersi padat meloksikam dengan matriks campuran PEG 6000 dan poloxamer 188 yang dibuat menggunakan metode kombinasi}

Keywords:

Meloxicam, PEG

6000, Poloxamer

188, Solid

Dispersion,

Combination

Method,

Characterization

\section{A B S T R A C T}

Meloxicam is one of the NSAID drugs indicated to relieve pain and inflammation in rheumatic diseases. Meloxicam drug classification is included in the BCS class II which has low solubility and high permeability this can result in limiting drug absorption in the body. One of the efforts made in this study to increase the solubility of meloxicam is by forming a meloxicam solid dispersion system in a mixture of PEG 6000 and poloxamer 188 at a ratio of 99:1 and 98:2 with a combination method which is then compared with the physical mixture at the same ratio and pure compound. The results of the diffractogram using XRPD, solid dispersion with a ratio of 99: 1 and 98: 2 show the formation of peaks with a smaller degree of sharpness or intensity at an angle of $13.5^{\circ} ; 15.0^{\circ}$; and $18.5^{\circ}$. The thermogram using DSC shows a decrease in the degree of crystallinity in the solid dispersion system with a ratio of 99:1 and 98:2, namely at the melting point of $56.1^{\circ} \mathrm{C}$ and $55.4^{\circ} \mathrm{C}$. The results of characterization by FT-IR showed that the solid dispersion system did not have chemical interactions between meloxicam with PEG 6000 and poloxamer 188. 


\section{Pendahuluan}

Kelarutan obat yang rendah dalam air merupakan faktor yang dapat mempengaruhi bioavailibilitas obat, karena hal tersebut menentukan kecepatan absorbsi pada obat (Varshosaz et al., 2008). Absorbsi obat dalam tubuh akan lebih lambat apabila suatu obat memiliki kelarutan yang rendah (Sharma et al., 2009). Salah satu contoh obat yang memiliki kelarutan rendah yaitu meloksikam. Berdasarkan data kelarutan meloksikam praktis tidak larut air $(0,012 \mathrm{~g} / \mathrm{L})$, sedangkan dalam dua pelarut campur (sistem biner) pelarut etanol sebesar $0,354 \mathrm{~g} / \mathrm{L}$, meloksikam dalam PEG-400 sebesar 3,763 g/L, atau meloksikam 4,023 g/L dalam pelarut campur PEG-400 dan etanol dengan perbandingan (9:1) (Jouyban, 2010).

Meloksikam adalah obat anti inflamasi non steroid (Sweetman, 2009). Kelarutan dan laju disolusi meloksikam yang rendah dalam media air dapat membatasi penyerapan obat dalam tubuh karena meloksikam termasuk dalam klasifikasi BCS kelas II (Biopharmaceutic Classification System class II) dimana kelarutannya yang rendah dan permeabilitasnya yang tinggi (Ambrus et al., 2009). Untuk mengatasi masalah tersebut, perlu dilakukan upaya untuk meningkatkan kelarutan meloksikam, salah satunya yaitu dengan teknik dispersi padat.

Penelitian yang sebelumnya dilakukan oleh (Issa et al., 2013) dengan bahan aktif meloksikam dan bahan pembawa poloxamer 188 menggunakan teknik dispersi padat metode peleburan dengan berbagai perbandingan rasio $(1 ; 2,1: 5$, dan 1:8) dan perbandingan suhu pendinginan $\left(5,15\right.$, dan $\left.25^{\circ} \mathrm{C}\right)$, menunjukkan bahwa peningkatan yang signifikan laju disolusi terjadi pada dispersi padat rasio 1:2, 1:5, 1:8 dengan suhu pendinginan $5^{\circ} \mathrm{C}$ yaitu masing-masing memiiliki laju disolusi sebesar $85,94 \%, 83,78 \%$ dan $90,93 \%$. Hal tersebut membuktikan bahwa rasio penambahan poloxamer 188 dan pengurangan suhu juga dapat mempengaruhi peningkatan kelarutan dan laju disolusi pada pembentukan sistem dispersi padat, karena poloxamer 188 merupakan surfaktan yang memiliki mekanisme kerja menurunkan tegangan permukaan, menurunkan sudut kontak sehingga pembasahan laju disolusi dapat meningkat.

Teknik dispersi padat adalah metode mendispersikan obat dalam pembawa inert (biasanya polimer yang larut dalam air) dalam bentuk padat (Zhang et al., 2018). Dispersi padat dapat menghasilkan pengendapan obat dalam keadaan amorf dengan kelarutan dan laju disolusi yang lebih tinggi daripada keadaan kristal (Younis, 2017). Pembuatan dispersi padat dapat dilakukan dengan beberapa metode, yaitu metode penguapan pelarut, metode peleburan, dan metode campuran atau kombinasi (Tran et al., 2019).

Metode kombinasi pada pembuatan dispersi padat dapat digunakan untuk obat-obatan yang termolabil dengan titik leleh tinggi (Kannao et al., 2014). Penelitian sebelumnya yang dilakukan oleh (Chen et al., 2009) pada 10-hydroxycamptothecin dengan PEG 6000 sebagai pembawa dan metanol sebagai pelarut menggunakan sistem dispersi padat metode kombinasi peleburan dan penguapan pelarut menunjukkan adanya peningkatan kelarutan sehingga dapat meningkatkan laju disolusi 10hydroxycamptothecin yang tidak larut dalam air. Keuntungan metode kombinasi pada pembuatan dispersi padat yaitu, dapat digunakan untuk obat-obatan yang termolabil dengan titik leleh tinggi (Kannao et al., 2014). Pembuatan metode ini hanya terbatas pada obat-obatan dengan dosis terapi rendah di bawah $50 \mathrm{mg}$ (Singh et al., 2013).

Teknik dispersi padat metode kombinasi dibuat menggunakan poloxamer 188 sebagai surfaktan karena dapat menurunkan tegangan permukaan dan menurunkan sudut kontak sehingga pembasahan laju disolusi dapat meningkat. Konsentrasi poloxamer 188 sebagai surfaktan perlu diperhatikan dari segi safety, quality, efficacy, dan acceptability, sehingga pemilihan perbandingan dipilih berdasarkan dari rentang pemakaian maksimum poloxamer 188, yaitu 0,8 - 2,0 \% (Healing et al., 2016). Sedangkan, pada penelitian Gozali, et al., 2015 menyebutkan bahwa pembuatan dispersi padat dengan pembawa polimer PEG 6000 memiliki stabilitas penyimpanan yang baik dibanding dengan PVP k30, kitosan $16 \mathrm{kDa}$, kitosan $11 \mathrm{kDa}$, dan PEG 4000. Selain itu berat molekul polietilen glikol yang lebih tinggi (PEG 6000) menghasilkan laju disolusi yang lebih tinggi karena dengan viskositas yang lebih tinggi dapat menghambat rekristalisasi (Obaidat et al., 2017).

Berdasarkan penjelasan diatas, penelitian ini bertujuan untuk mengetahui karakterisasi sistem fisikokimia dispersi padat meloksikam dengan menggunakan PEG 6000 sebagai polimer dan poloxamer 188 sebagai surfaktan dengan perbandingan polimer:surfaktan (99:1 dan 98:2) menggunakan metode kombinasi. Sistem dispersi padat yang telah jadi dapat dikarakterisasi dengan menggunakan Differential Scanning Calorimetry (DSC), X-Ray Powder Diffraction (XRPD), dan Fourier Transformed Infrared Spectroscopy (FTIR).

\section{Metode}

\section{Bahan}

meloksikam, PEG 6000 , poloxamer 188, ethanol $96 \%$ p.a.

\section{Alat}

Alat yang digunakan pada penelitian ini yaitu timbangan analitik, beaker glass, cawan porselen, sendok tanduk, pipet tetes, hot plate, water bath, batang pengaduk, termometer, dry ice, ice bath, desikator, mortir dan stamper, ayakan mesh no 60, stopwatch, X-Ray Powder Diffraction (XRPD), Differential Scanning Calorimetry (DSC) Spektrofotometer IR, Spektrofotometer UV-VIS dan dissolution tester tipe dayung.

\section{Pembuatan Campuran Fisik}

Meloksikam, PEG 6000 dan Poloxamer 188 ditimbang berdasarkan perbandingan masing-masing pada tiap variasi konsentrasi yang kemudian dicampur dalam mortir sambil diaduk menggunakan stamper. 


\section{Pembuatan Dispersi Padat dengan Metode Kombinasi}

Meloksikam, PEG 6000 dan Poloxamer 188 ditimbang berdasarkan perbandingan masing-masing pada tiap variasi konsentrasi yang dibuat. Campuran PEG 6000 dan Poloxamer 188 dipanaskan atau dilebur menggunakan water bath pada suhu $56^{\circ} \mathrm{C}-60^{\circ} \mathrm{C}$ selama $10-15$ menit hingga semua campuran meleleh. Kemudian dimasukan meloksikam yang dilarutkan etanol $96 \%$ p.a sedikit demi sedikit (setiap $20 \mathrm{~mL}$ ) kedalam leburan tersebut dan dilakukan pengadukan hingga tercampur rata dan etanol telah menguap. Hasil lelehan disimpan pada suhu $-5^{\circ} \mathrm{C}$ selama 24 jam menggunakan dry ice agar memadat, kemudian bentuk padatan sampel dihancurkan menjadi serbuk dan diayak dengan ayakan berukuran $250 \mu \mathrm{m}$.

\section{Karakterisasi menggunakan Difraksi Serbuk Sinar-X (X-Ray PowderDiffraction/XRPD)}

Uji difraksi serbuk sinar-X ini dilakukan pada meloksikam murni, PEG 6000 murni, Poloxamer 188 murni, campuran fisik dan dispersi padat. Menimbang masing- masing sampel sebanyak 5-10 mg. Setiap sampel dimasukkan ke dalam holder kaca sampai penuh dan diratakan dengan lempeng kaca. Sampel pada holder kaca dimasukkan kedalam alat pada suhu ruang dan diamati dengan rentang sudut $2 \theta$ dari $5-50^{\circ}$. Difraksi serbuk sinar$\mathrm{X}$ diatur pada target logam $\mathrm{Cu}$, filter $\mathrm{K} \alpha$, tegangan $40 \mathrm{kV}$, dan arus $40 \mathrm{~mA}$ (Kreidel et al., 2012).

\section{Karakteriasi Uji Thermal dengan DSC}

Uji thermal dilakukan menggunakan alat Differential Scanning Calorimetry (DSC) terhadap meloksikam murni, PEG 6000, Poloxamer 188, campuran fisik, dan dispersi padat. Menimbang masing-masing sampel sebanyak 5-10 mg. Dipindahkan ke dalam krus aluminium, kemudian pan aluminium dimasukkan ke dalam alat DSC. Alat diatur dengan kecepatan pemanasan $10^{\circ} \mathrm{C} /$ menit dan pengamatan dilakukan dalam rentang suhu $25-300^{\circ} \mathrm{C}$ (Kreidel et al., 2012)

\section{Karakterisasi dengan Spektrofotometer FT-IR}

Spektrum inframerah meloksikam murni, PEG 6000, Poloxamer 188, campuran fisik, dan dispersi padat dibuat dengan metode pelet KBr. Serbuk sampel KBr1\% $\mathrm{b} / \mathrm{b}$ disiapkan dengan cara menggerus serbuk sampel dan $\mathrm{KBr}$ pada mortar hingga homogen. Campuran tersebut dimasukkan ke dalam pengering hampa udara, dicetak dengan penekan hidrolik sampai diperoleh cakram yang transparan. Cakram yang terbentuk dimasukkan dalam sampel holder dan disinari dengan sinar inframerah, lalu diamati pita serapan pada bilangan gelombang 4000-500 $\mathrm{cm}^{-1}$ (Al-Nima et al., 2014).

\section{Hasil dan Diskusi}

\section{Difraksi Serbuk Sinar-X (X-Ray Powder Diffraction / XRPD}

Teknik difraksi serbuk sinar-x sering digunakan untuk mengidentifikasi penetapan kemurnian bahan yang berbentuk hablur. Bentuk hablur dari suatu senyawa dapat menghasilkan pola difraksi sinar-X yang khas (Depkes RI, 2014).

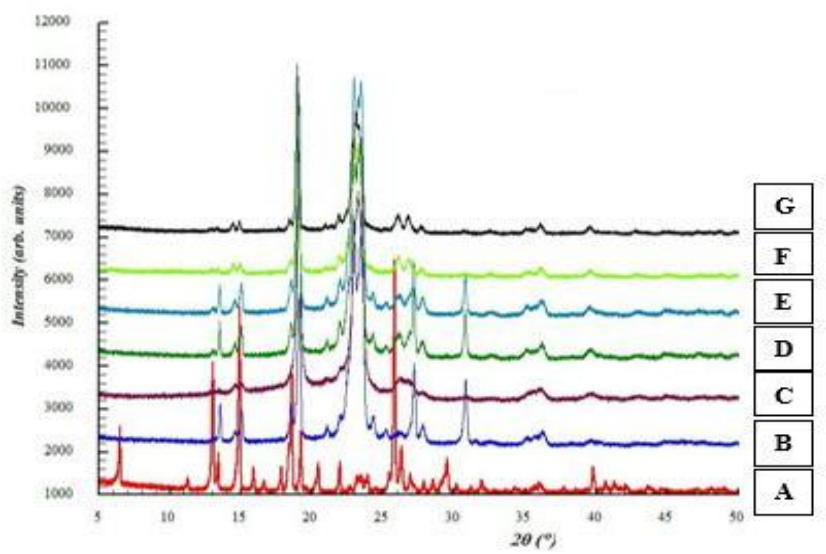

Gambar 1. Perbandingan difraktogram dari meloksikam (A), PEG 6000 (B), poloxamer 188 (C), CF-1 (D), CF-2 (E), DP-1 (F), dan DP-2 (G).

\begin{tabular}{|c|c|c|c|c|c|c|c|c|}
\hline \multirow{3}{*}{ No. } & \multirow{3}{*}{$2 \theta$} & \multicolumn{7}{|c|}{ Intensitas Relatif (\%) } \\
\hline & & \multirow{2}{*}{$\begin{array}{c}\text { Meloksi- } \\
\text { kam }\end{array}$} & \multirow{2}{*}{$\begin{array}{l}\text { PEG } \\
6000\end{array}$} & \multirow{2}{*}{$\begin{array}{l}\text { Poloxa- } \\
\text { mer } 188\end{array}$} & \multicolumn{2}{|c|}{$\begin{array}{c}\text { Campuran } \\
\text { Fisik }\end{array}$} & \multicolumn{2}{|c|}{ Dispersi Padat } \\
\hline & & & & & $\begin{array}{l}\text { CF-1 } \\
(99: 1)\end{array}$ & $\begin{array}{r}\text { CF-2 } \\
(98: 2)\end{array}$ & $\begin{array}{l}\text { DP-1 } \\
(99: 1)\end{array}$ & $\begin{array}{l}\text { DP-2 } \\
(98: 2)\end{array}$ \\
\hline 1. & 5,2 & - & 0,85 & - & - & - & - & - \\
\hline 2. & 6,5 & 24,40 & - & - & - & - & - & - \\
\hline 3. & 11,2 & 4,49 & - & - & - & - & - & - \\
\hline 4. & 13,5 & 14,58 & 16,25 & 0,96 & 14,16 & 10,97 & 2,16 & 1,98 \\
\hline 5. & 15,0 & 77,65 & 11,14 & 3,60 & 12,24 & 10,72 & 5,22 & 5,85 \\
\hline 6. & 18,5 & 50,94 & 15,51 & - & 13,44 & 13,70 & 6,56 & 7,32 \\
\hline 7. & 21,0 & - & 7,38 & 5,33 & 6,06 & 5,90 & 4,88 & 3,62 \\
\hline 8. & 23,5 & 6,59 & 92,73 & 93,11 & 90,48 & 77,67 & - & 44,5 \\
\hline 9. & 26,2 & 19,24 & 4,28 & 8,27 & 9,04 & 7,52 & 10,31 & 10,24 \\
\hline 10. & 27,7 & - & 7,70 & 2,55 & 6,20 & 6,90 & 3,79 & 3,66 \\
\hline
\end{tabular}

Tabel 1. Difraktogram sinar-X meloksikam, PEG 6000, poloxamer 188, campuran fisik dan dispersi padat

Meloksikam merupakan senyawa yang memiliki bentuk kristalin. Pada pengujian XRPD ini dilakukan dengan rentang sudut $2 \theta$ dari $5^{\circ}$ sampai $50^{\circ}$ dengan target $\operatorname{logam} \mathrm{Cu}$ dan filter $\mathrm{K} \alpha$. Hasil uji XRPD pada senyawa murni meloksikam, PEG 6000, dan poloxamer 188 menunjukkan adanya puncak tajam yang spesifik pada difraktogram. Menurut (Badawi et al., 2019) kristanilitas suatu senyawa dapat dilihat dari adanya puncak difraksi yang tajam pada difraktogram. Senyawa meloksikam murni menunjukkan puncak yang tajam dan difraksi khas $2 \theta\left(6,5^{\circ} ; 15,0^{\circ}\right.$; dan $\left.18,5^{\circ}\right)$. PEG 6000 menunjukkan difraksi khas pada sudut $2 \theta\left(18,5^{\circ}\right.$ dan $\left.23,5^{\circ}\right)$. Sedangkan pada poloxamer 188 menunjukkan puncak khas pada sudut $2 \theta\left(23,5^{\circ}\right)$. Pada DP-1 dan DP-2 hilangnya puncak terlihat pada sudut $5,2^{\circ}$ dan terbentuknya puncak dengan tingkat ketajaman atau instensitas yang lebih kecil pada sudut $13,5^{\circ} ; 15,0^{\circ}$; dan $18,5^{\circ}$. Hasil data XRPD dari penelitian ini menunjukkan bahwa sistem dispersi padat sudah terbentuk dengan menggunakan metode kombinasi, hal tersebut ditunjukkan dengan terjadinya penurunan 
intensitas sehingga dapat menurunkan derajat kristanilitas dari meloksikam. Namun, hasil pada DP-2 memiliki intensitas lebih kecil daripada DP-1 walaupun perbedaan selisihnya tidak terlalu jauh. DP-2 memiliki intensitas lebih kecil dikarenakan jumlah surfaktan (poloxamer 188) yang ditambahkan lebih banyak daripada DP-1. Sehingga, peningkatan laju disolusi dapat terjadi karena berkurangnya agregasi partikel obat (Prasanthi et al., 2011).

\section{DSC (Differential Scanning Calorimetry)}

Differential Scanning Calorimetry (DSC) merupakan salah satu teknik analisis termal yang paling banyak digunakan untuk mengetahui titik lebur suatu bahan (Setyawan et al., 2018). Data dari hasil DSC yaitu suhu leleh, suhu kristalisasi, peristiwa thermal, suhu transisi gelas, serta interaksi antara obat dan obat atau obat dan eksipien (Chieng et al., 2011).
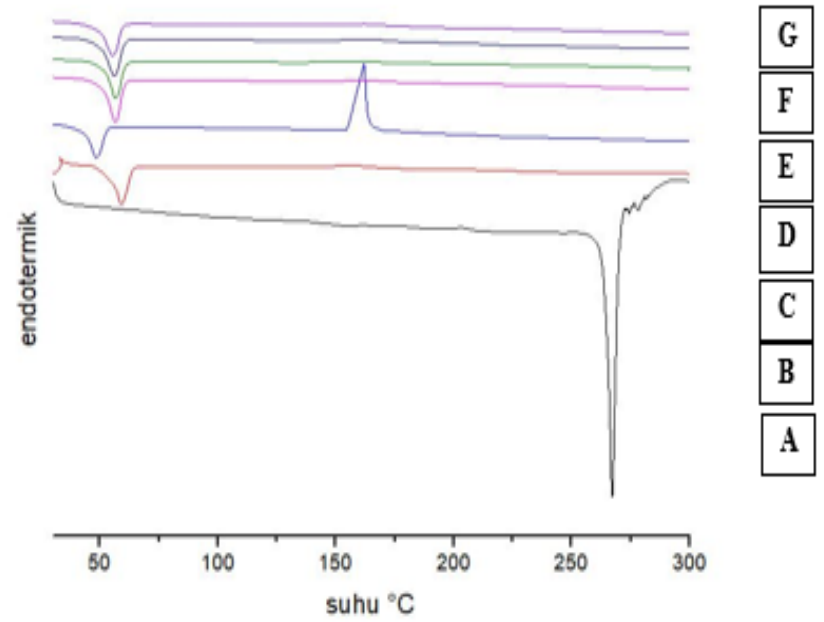

Gambar 2. Perbandingan termogram dari meloksikam (A), PEG 6000 (B), poloxamer 188 (C), CF-1 (D), CF-2 (E), DP-1 (F), dan DP-2 (G)

\begin{tabular}{clc} 
No. & \multicolumn{1}{c}{ Sampel } & Puncak Endotermik $\left({ }^{\circ} \mathrm{C}\right)$ \\
\hline 1. & Meloksikam & 264,82 \\
\hline 2. & PEG 6000 & 59,3 \\
\hline 3. & Poloxamer 188 & 48,5 \\
\hline 4. & CF-1 & 57,2 \\
\hline 5. & CF-2 & 56,6 \\
\hline 6. & DP-1 & $56,1^{*}$ \\
\hline 7. & DP-2 & $55,4^{*}$ \\
\hline
\end{tabular}

Tabel 2. Puncak endotermik meloksikam, PEG 6000, poloxamer 188, campuran fisik dan dispersi padat

Pada penelitian ini digunakan analisis termal menggunakan DSC untuk mengetahui perbandingan titik lebur dari senyawa murni meloksikam, PEG 6000, poloxamer 188 dengan sediaan yang telah dibuat dalam bentuk campuran fisik dan dispersi padat. Hasil termogram meloksikam menunjukkan puncak endotermik pada suhu $264,82^{\circ} \mathrm{C}$, PEG 6000 pada suhu $59,3^{\circ} \mathrm{C}$, sedangkan poloxamer 188 pada suhu $48,5^{\circ} \mathrm{C}$. Kemudian, hasil termogram pada $\mathrm{CF}-1$ dan $\mathrm{CF}-2$ puncak endotermik masing-masing terjadi pada suhu $57,2^{\circ} \mathrm{C}$ dan $56,6^{\circ} \mathrm{C}$. DP-1 dan DP-2, menunjukkan adanya perubahan titik lebur pada suhu $56,1^{\circ} \mathrm{C}$ dan $55,4^{\circ} \mathrm{C}$. Hasil termogram dari DP-1 maupun DP-2 menandakan telah terjadi pergeseran titik lebur dibandingkan dengan senyawa murni meloksikam, hal tersebut menunjukkan bahwa sistem dispersi padat dapat mengurangi derajat kristalinitas pada suatu sediaan. Titik lebur pada DP-1 dan DP-2 tidak terlalu jauh dikarenakan adanya proses pemanasan pada pembentukan sistem dispersi padat. Tetapi, DP-2 memiliki titik lebur yang lebih rendah dibanding DP-1 karena poloxamer 188 sebagai surfaktan yang ditambahkan lebih banyak dibanding DP-1. Pengurangan derajat kristanilitas ditunjukkan dengan penurunan entalpi dimana jumlah energi yang dibutuhkan untuk pelelehan lebih rendah (Wardiyah et al., 2012).

\section{Spektrofotometer FT-IR}

Spektroskopi FT-IR dapat digunakan untuk menunjukkan adanya interaksi antara obat dan pembawa dalam keadaan padat (Chieng et al., 2011).

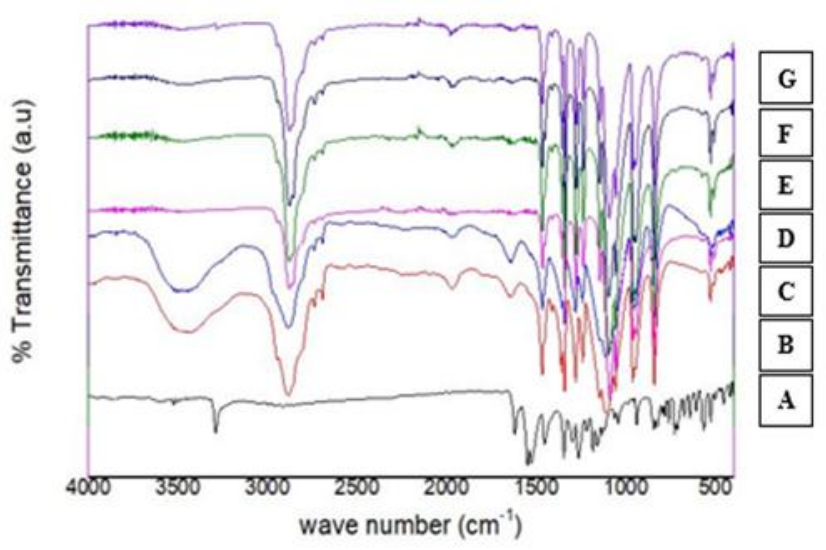

Gambar 3. Perbandingan spektrum inframerah dari meloksikam (A), PEG 6000 (B), poloxamer 188 (C), CF-1 (D), CF-2 (E), DP-1 (F), dan DP-2 (G)

\begin{tabular}{|c|c|c|c|c|c|c|c|}
\hline \multirow{2}{*}{$\begin{array}{l}\text { Gugus } \\
\text { Fungsi }\end{array}$} & \multirow{2}{*}{$\begin{array}{c}\text { Meloksi- } \\
\text { kam }\end{array}$} & \multirow{2}{*}{$\begin{array}{l}\text { PEG } \\
6000\end{array}$} & \multirow{2}{*}{$\begin{array}{l}\text { Poloxa- } \\
\text { mer } 188\end{array}$} & \multicolumn{2}{|c|}{ Campuran Fisik } & \multicolumn{2}{|c|}{ Dispersi Padat } \\
\hline & & & & CFl & CF2 & DP1 & DP2 \\
\hline$-\mathrm{NH}$ & 3290,67 & - & - & - & - & - & - \\
\hline$-\mathrm{OH}$ & - & 3446,91 & 3466,20 & - & - & - & - \\
\hline $\mathrm{C}-\mathrm{H}$ & 2916,47 & 2889,46 & 2887,53 & 2877,14 & 2878,95 & 2881,93 & 2877,78 \\
\hline $\mathrm{C}=\mathrm{N}$ & 1691,63 & - & - & - & - & - & - \\
\hline $\mathrm{C}=0$ & 1620,26 & - & - & - & - & - & - \\
\hline $\mathrm{C}=\mathrm{C}$ & 1548,89 & - & - & - & - & - & - \\
\hline $\begin{array}{c}\mathrm{S}=0 \\
\text { (sulfon) }\end{array}$ & 1346,36 & - & - & 1340,55 & 1340,79 & 1340,38 & 1340,68 \\
\hline $\mathrm{C}-\mathrm{N}$ & 1265,35 & - & - & 1278,53 & 1278,61 & 1278,77 & 1278,56 \\
\hline $\mathrm{C}-0$ & - & 1112,96 & 1112,96 & 1145,49 & 1145,88 & 1146,81 & 1145,96 \\
\hline
\end{tabular}

Tabel 3. Perbandingan hasil interpretasi bilangan gelombang meloksikam, PEG 6000, poloxamer 188, campuran fisik dan dispersi padat

Spektroskopi FT-IR pada penilitian ini juga dilakukan dengan tujuan untuk mengetahui ada atau tidaknya interaksi antara obat dan pembawa dalam keadaan padat. Analisis FT-IR dilakukan pada bilangan gelombang $4000-400 \mathrm{~cm}^{-1}$. Berdasarkan hasil pengujian spektrum FTIR dari campuran fisik dan dispersi padat yang teridentifikasi, maka pita-pita serapan masuk ke dalam 
rentang spektrum karakteristik meloksikam murni, PEG 6000, dan poloxamer 188. Spektrum FT-IR pada DP-1 dan DP-2 menunjukkan adanya pergeseran bilangan gelombang dari meloksikam, PEG 6000 dan poloxamer $188 \mathrm{Hal}$ tersebut menunjukkan tidak adanya interaksi kimia antara meloksikam dengan PEG 6000 dan poloxamer 188.

\section{Daftar Pustaka}

1. Al-Nima AM, Al-Kotaji MM, Khayrallah AA. Preparation and evaluation of meloxicam solid dispersions by solvent evaporation method. Int Res J Pharm. 2014;5(11):838-45.

2. Ambrus R, Kocbek P, Kristl J, Šibanc R, Rajkó R, Szabó-Révész P. Investigation of preparation parameters to improve the dissolution of poorly water-soluble meloxicam. International journal of pharmaceutics. 2009 Nov 3;381(2):153-9.

3. Badawi A, Geneidi AS. Enhancing dissolution of artesunate from immediate release tablets using a green granulation technique. Archives of Pharmaceutical Sciences Ain Shams University. 2019 Jan 1;3(1):55-77.

4. Chen H, Jiang G, Ding F. Monolithic osmotic tablet containing solid dispersion of 10hydroxycamptothecin. Drug development and industrial pharmacy. 2009 Feb 1;35(2):131-7.

5. Chieng N, Rades T, Aaltonen J. An overview of recent studies on the analysis of pharmaceutical polymorphs. Journal of pharmaceutical and biomedical analysis. 2011 Jun 25;55(4):618-44.

6. Departemen Kesehatan RI, editor, Farmakope Indonesia, Edisi Ke-5, Departemen Kesehatan RI, Jakarta, 2014.

7. Gozali, D., Wardhana, Y. W., \& Shofa, S. Formulasi dan evaluasi tablet dispersi padat kalsium atorvastatin. Jurnal Pharmascience. 2019, vol. 2, no.2, pp. 63-70.

8. Issa AA, Marchidan D, Cojocaru V, Anuța V. Preparation and evaluation of meloxicam solid dispersion by melting method. Farmacia. 2013 Nov 1;61(6):1213-32.

9. Jouyban, A, editor. Handbook of Solubility Data for Pharmaceutical. NewYork: CRCPress Taylor \& Francis Group, LLC, 2010, pp.382.

10. Kannao SU, Bakade BV. Solid Dispersion-A Technique for Solubility Enhancement of Weakly Water Soluble Drug-A Review. Indo American Journal of Pharm Research. 2014;4(6).

11. Kreidel RN, Duque MD, Serra CH, Velasco MV, Baby AR, Kaneko TM, Consiglieri VO. Dissolution enhancement and characterization of nimodipine solid dispersions with poloxamer 407 or PEG 6000. Journal of dispersion science and technology. 2012 Sep 1;33(9):1354-9.

12. Obaidat R, Al-taani B, Al-quraan HA. Effect of selected polymer on dissolution and stabilization of amorphous form of meloxicam. Int $\mathrm{J}$ Pharm Pharm Sci. 2017;9(9):3342.
13. Prasanthi NL, Manikiran SS, Sowmya S, Anusha B, Rao NR. Effect of poloxamer 188 on in vitro dissolution properties of antipsychotic solid dispersions. Int J Pharm Sci Rev Res. 2011;10(1):159.

14. Sharma D, Soni M, Kumar S, Gupta GD. Solubility enhancement-eminent role in poorly soluble drugs. Research Journal of Pharmacy and Technology. 2009 Apr;2(2):220-4.

15. Setyawan D, Jovita RO, Iqbal M, Paramanandana A, Yusuf H, Lestari ML. Co-crystalization of quercetin and malonic acid using solvent-drop grinding method. Tropical Journal of Pharmaceutical Research. 2018;17(6):997-1002.

16. Singh J, Walia M, Harikumar SL. Solubility enhancement by solid dispersion method: a review. Journal of drug delivery and Therapeutics. 2013 Sep $14 ; 3(5): 148-55$.

17. Sweetman, Sean C, editor. Martindale The Complete Drug Reference. 36th Ed, Pharmaceutical Press, Usa, 2009, pp. 81.

18. Tran P, Pyo YC, Kim DH, Lee SE, Kim JK, Park JS. Overview of the manufacturing methods of solid dispersion technology for improving the solubility of poorly water-soluble drugs and application to anticancer drugs. Pharmaceutics. 2019 Mar;11(3):132.

19. Varshosaz, J. A., Talari, R., Mostafavi, S. A., Nokhodchi, A. Dissolution Enhancement Of Gliclazide Using In Situ Micronization By Solvent Change Method. Powder Technology. 2008, vol. 187, no.3, pp. 222-230.

20. Wardiyah, W., Asyarie, S., Wikarsa, S. Pembuatan dan Karakterisasi Dispersi Padat Sistem Biner dan Terner dari Gliklazid. Acta Pharmaceutica Indonesia. 2012, vol. 37, no.3, pp. 95-101.

21. Younis MA. Solid dispersion technology, a contemporary overview on a well established technique. Universal Journal of Pharmaceutical Research. 2017;2(3):15-9.

22.Zhang X, Xing H, Zhao Y, Ma Z. Pharmaceutical dispersion techniques for dissolution and bioavailability enhancement of poorly water-soluble drugs. Pharmaceutics. 2018 Sep;10(3):74. 